\title{
Identificação e análise de manifestações patológicas em estruturas de concreto dos terminais de ônibus na cidade de Manaus
}

\author{
A. R. M. Colares ${ }^{1 *}$, H. M. Murchie ${ }^{1}$, R. P. Vasconcelos ${ }^{1}$ \\ *Autor de Contacto: eng.albertocolares@gmail.com \\ ${ }^{1}$ Departamento de Engenharia Civil, Faculdade de Tecnologia, Universidade Federal do Amazonas, Manaus, Brasil.
}

\begin{abstract}
RESUMO
O trabalho objetivou identificar e analisar as possíveis manifestações patológicas presentes nos terminais de ônibus da cidade de Manaus, especificamente nas estruturas de concreto e alvenaria de vedação, buscando na literatura técnica soluções adequadas para cada caso. Das visitas aos terminais, observou-se que as manifestações mais frequentes foram trincas, desplacamento de camada de concreto, oxidação de armaduras expostas, empoçamento de água em laje e avarias por choque mecânico. Mostrou-se que, em geral, esses problemas se originaram em falhas executivas e de uso, contato de água intermitente com a estrutura, vibração pelo tráfego de veículos pesados e em carbonatação do concreto por conta da elevada concentração de gás carbônico no local. Isso posto, tratamentos recomendados variaram conforme o grau de risco.
\end{abstract}

Palavras chave: Terminais; Ônibus; Patologia; Concreto; Manaus.

\section{RESUMEN}


El trabajo tuvo como objetivo identificar y analizar las posibles manifestaciones patológicas presentes en las terminales de autobuses de Manaus, específicamente en estructuras de sellado de hormigón y mampostería, buscando en la literatura técnica soluciones para cada caso. Se observó que las manifestaciones más frecuentes fueron grietas, desprendimiento de la capa de concreto, oxidación de armaduras expuestas, charcos de agua de losa y daños por choque mecánico. Se demostró que, por lo general, estos problemas se originaban en fallas ejecutivas y de uso, contacto intermitente del agua con la estructura, vibraciones ocasionadas por el tránsito de vehículos pesados y la carbonatación del concreto por la alta concentración de dióxido de carbono. Los tratamientos recomendados variaron según el grado de riesgo.

Palabras clave: Terminales; Autobuses; Patología; Hormigón; Manaus.

\begin{abstract}
The research purposed to identify and to analyze possible pathological manifestations present in bus terminals at Manaus city, specifically in reinforced concrete structures and sealing masonry, searching in technical literature the correct solution to each problem. Was observed that most frequent manifestations were fissures, fall of the protective layer of reinforced bars, steel oxidation, water accumulation on slabs and damage by mechanical crash. Generally, these problems have origin on executive and utilization fails, on excessive contact with water, on vibration by big vehicle traffic and on carbonation of the concrete by the local high rate of carbon dioxide. The recommendation of treatment depends on the degree of risk.
\end{abstract}

Keywords: Terminals; Bus; Pathology; Concrete; Manaus.

\title{
1. INTRODUÇÃO
}

O processo de crescimento urbano demanda do poder público a promoção da cidadania daqueles que moram em território de sua jurisdição. Nesse contexto, o sistema transporte coletivo urbano exerce protagonismo no exercício da cidadania, pois garante o exercício do direito de ir e vir, previsto no artigo $6^{\circ}$ da Constituição Federal (Brasil, 1988). Além disso, como atividade-meio, o transporte coletivo é um dos elementos essenciais na movimentação econômica de um lugar, já que, como explicam Junior e Rangel (2017), é ele que possibilita o deslocamento dos trabalhadores para o exercício de suas atividades cotidianas.

No caso da cidade de Manaus, o sistema de transporte coletivo é feito por meio de ônibus e, para algumas regiões, micro-ônibus executivos. Para os ônibus, conforme o portal da Superintendência Municipal de Transportes Urbanos (SMTU, 2018), o sistema é do tipo tronco-alimentado: as linhas se deslocam dos bairros em direção a terminais de integração ou conexão em um ponto intermediário entre origem e destino, nos quais as pessoas podem embarcar em outros ônibus para finalização da viagem. Há na cidade seis terminais de integração espalhados nas diferentes zonas, além de terminais de conexão com grande movimento de pessoas, como o Terminal da Matriz e a Estação de Transferência São Jorge.

O sistema em si tem atendido regularmente a dinâmica da cidade, no entanto as condições de infraestrutura dos terminais, resultantes da manutenção deficiente, causam grande incômodo aos seus usuários, como mostrou Benoliel (2018). Isto é um problema que deve ser encarado continuamente, pois as condições de conforto interferem diretamente na qualidade de vida e produtividade do trabalhador. 
Partindo disto, a pesquisa teve como objetivo analisar as manifestações patológicas nas estruturas de concreto e alvenaria de vedação dos cinco primeiros terminais de integração de ônibus da cidade de Manaus, indicando as possíveis soluções para o problema.

\section{REVISÃO BIBLIOGRÁFICA}

\subsection{Fatores de ocorrência de anomalias nas estruturas de concreto}

Para Vieira (2016), as manifestações patológicas podem se originar nas etapas de concepção, execução e utilização da estrutura. Quando se originam da concepção, tendem a ter soluções mais complexas e, por consequência, mais onerosas. Na fase de execução, é importante o cuidado com a correta interpretação dos projetos pelos executores, bem como a qualidade da mão-de-obra, pois o desconhecimento dos trabalhadores quanto ao manuseio dos materiais pode fazer com que, por exemplo, um pilar seja preenchido de forma incompleta e, ainda, segregada. Já na fase de utilização, os problemas surgem da utilização inadequada por parte dos usuários, bem como da ausência ou deficiência nas ações de manutenção.

Estruturas de concreto armado podem apresentar problemas que decorrem de agentes agressivos diversos. Bolina et. al. (2019) afirmam que no passado acreditava-se que o concreto armado era eterno, dado seu desempenho satisfatório em uma variedade de ambientes, no entanto essa visão foi mudando ao longo do tempo, à medida que se conheceu mais sobre o material. Para Souza e Ripper (1998), fatores como qualidade dos materiais, manutenção inadequada ou ausente, mau uso da estrutura e intemperismo físico e químico levam ao aparecimento de manifestações patológicas como infiltrações, manchas de fungo, fissuras, rachaduras, recalque diferencial, carbonatação e eflorescência, sendo essas duas últimas próprias do concreto.

De origem química e física combinada, a carbonatação do concreto, segundo Pauletti (2009), não é um fator prejudicial para o concreto em si, mas um ponto de atenção importante para o concreto armado, pois facilita a corrosão das armaduras. Na verdade, Souza e Ripper (1998) afirmam que, se não alcançasse o nível da armadura, a carbonatação favoreceria a estrutura, garantindo melhoria tanto em resistência mecânica como em resistência química. Ribeiro e Cunha (2014, apud Barbosa Filha et. al., 2016) explica que ela ocorre quando o gás carbônico presente na atmosfera reage com o hidróxido de cálcio do concreto, formando o carbonato de cálcio. O fenômeno é favorecido quando há grande quantidade de poros e umidade elevada. Poggiali (2009) explica que em ambientes urbanos e industriais, o ar pode estar contaminado com níveis elevados de agentes agressivos ao concreto, como o dióxido de carbono, gás sulfídrico, gás de amônia, entre outros. Esclarece ainda que "a carbonatação ocorre de forma mais acelerada em concretos de baixa qualidade e em ambientes com umidade relativa variando entre 50\% e 70\%" (Poggiali, 2009). No caso de Manaus, que, segundo dados do Instituto Nacional de Meteorologia (INMET, 2021), costuma ter valores de umidade relativa do ar acima de $70 \%$, cria-se um ambiente favorável à carbonatação, principalmente em locais dentro da área urbana onde há grande concentração e circulação de veículos, com consequente emissão maior de dióxido de carbono. Esse é o caso dos terminais de ônibus, objeto deste estudo, apesar de, segundo a NBR 6118 (ABNT, 2014), a classe de agressividade de projeto de ambiente urbano ser moderada, com risco pequeno de deterioração da estrutura.

A eflorescência também é comum no concreto. Uemoto (1988) explica que, constituída principalmente de sais de metais alcalinos e alcalino-terrosos, ocorre quando, pela ação da água intermitente, por exemplo da chuva, o elemento estrutural fica saturado e os sais presentes nele são dissolvidos e transportados para a superfície. Daí, por evaporação da solução, forma-se uma camada branca pulverulenta de sais depositados. De modo geral, causa apenas danos estéticos, mas serve para indicar um problema muito maior: umidade excessiva. 
Bolina et. al. (2019) reforçam que "a deterioração das estruturas de concreto dificilmente é relacionada a uma única origem", e que, em geral, manifestações patológicas se dão pela ação de diversos agentes, cuja atuação é simultânea. Daí a necessidade de a investigação das causas ser cuidadosa, pois essa sobreposição de mecanismos pode acrescentar dificuldades ao diagnóstico, e o erro na correta identificação da origem do problema pode levar a prejuízos tanto econômicos como estruturais e, no caso de edificações de interesse público, sociais.

\subsection{Impacto das manifestações patológicas no transporte coletivo}

Para relacionar de forma satisfatória os aspectos construtivos dos terminais de ônibus com o bemestar dos usuários, é necessário levar em consideração a ergonomia ambiental, que, segundo Alves et. al. (2010, apud Nasta, 2014):

"Atua em planejamentos e projetos do objeto ao ambiente construído de um modo geral, com abrangência no espaço urbano, áreas de convívio, de lazer e áreas verdes, na busca de soluções para promover o conforto, segurança e bem-estar aos indivíduos."

Seguindo essa ideia, infere-se que a simples existência de manifestações patológicas quebra, no local em que estão inseridas, a harmonização dos três pilares fundamentais da ergonomia ambiental: compromete, primeiramente, o bem-estar do usuário que percebe que algo está errado, aponta falhas de segurança estrutural e, por consequência, diminui o conforto de quem está inserido em um local com visíveis anomalias estruturais.

Considerar isso é importante para evitar o estresse do usuário pois, segundo Leite et. al. (2015) "existe uma grande relação entre o estresse vivido pelo trabalhador e seu nível de produtividade", o que impacta diretamente no ciclo de desenvolvimento urbano.

\section{MÉTODOS UTILIZADOS}

O terminais de integração de ônibus de Manaus estão distribuídos pela cidade conforme ilustrado pela Figura 1. Todos eles são dotados de estruturas metálicas e de concreto, sendo este último tipo o escopo do presente trabalho. Na época em que esta pesquisa foi realizada, a construção do Terminal 6 estava em processo de concepção, motivo pelo qual ele não foi objeto de estudo.

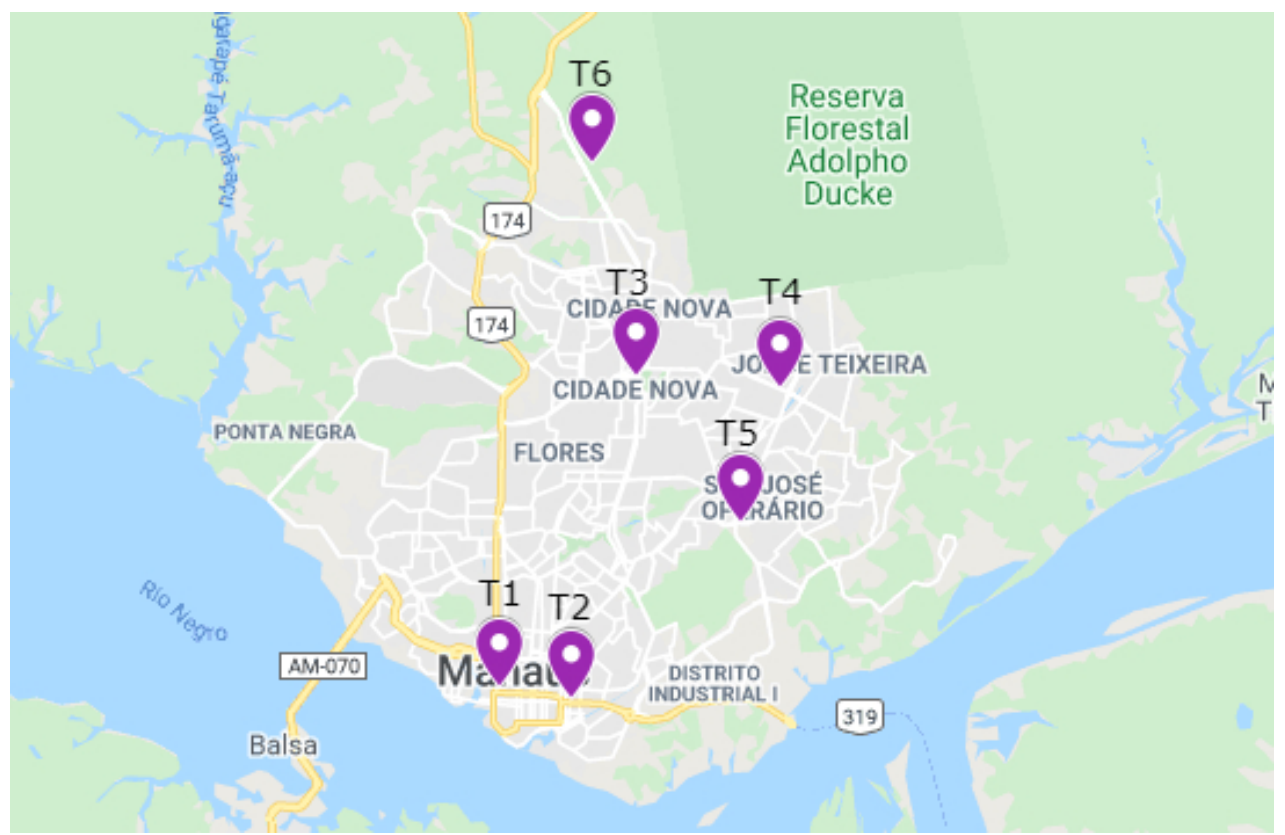

Figura 1. Distribuição dos terminais de ônibus na cidade de Manaus. Fonte: Google Maps, adaptado pelos autores (2021). 
Foi feito levantamento do estado da arte relativa ao tema da pesquisa, através de revisão bibliográfica por meio de pesquisa em artigos, revistas, teses, dissertações e livros didáticos relacionados à área de patologia e materiais de construção civil. Fez-se também a análise dos projetos e especificações dos cinco terminais de integração de ônibus da cidade de Manaus, o que é exemplificado na Figura 2, que mostra parte do layout do Terminal de Integração 1. Essa documentação foi cedida pela Secretaria Municipal de Infraestrutura de Manaus, que também autorizou a execução de visitas técnicas aos terminais de ônibus e disponibilizou pessoal para acompanhamento.

Na etapa de campo, fez-se estudos de caso por meio de inspeção predial para detecção de anomalias com uso de instrumentos como fissurômetro, paquímetro, trena e lupa, seguindo as recomendações da Norma de Inspeção Predial Nacional do Instituto Brasileiro de Avaliações e Perícias de Engenharia (IBAPE, 2012).

A partir disso, foi feita a identificação das manifestações patológicas encontradas, estudo de causas e efeitos a partir da análise do histórico dos problemas identificados, diagnóstico e listagem das manifestações patológicas e anomalias encontradas, finalizando com relatório das causas, classificação das anomalias e do estado geral dos terminais quanto ao grau de risco e sugestão de reparos e medidas preventivas.

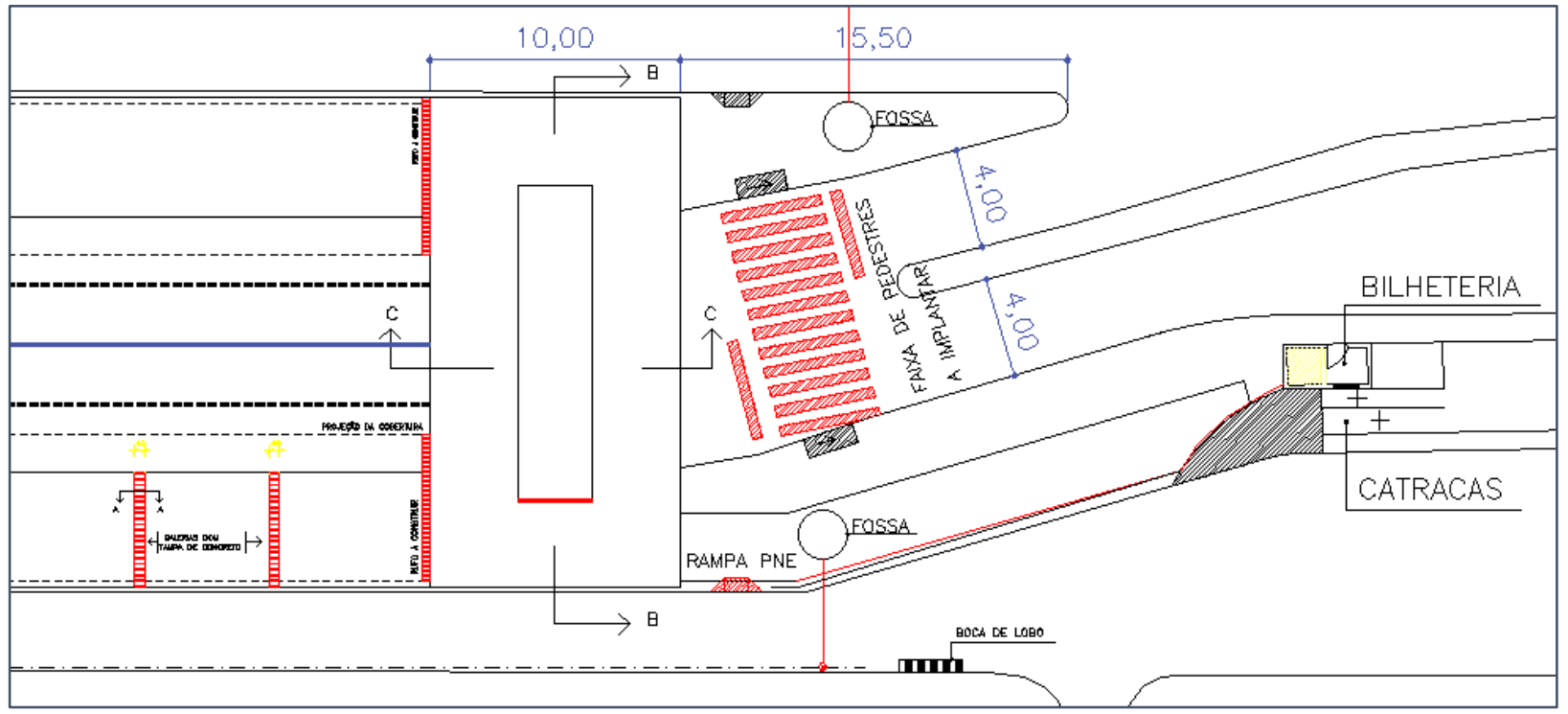

Figura 2. Parte do layout do Terminal de Integração 1. Fonte: EMTU (2012).

\section{RESULTADOS E DISCUSSÕES}

Após pesquisa de campo, fez-se o levantamento das manifestações patológicas encontradas e a quantificação das ocorrências absoluta, isto é, o número de terminais em que a anomalia foi detectada, e percentual, a razão vezes cem entre a ocorrência absoluta e o número total de terminais analisados (Tabela 1 e Figura 3). Em todos os terminais vistoriados foram detectados casos de trincas na alvenaria e em $80 \%$ deles foram detectados casos de perda de material por choque mecânico, empoçamento de água em pano de laje, desplacamento do cobrimento de concreto e oxidação de armadura. Em $60 \%$ dos casos encontrou-se rachaduras, mancha de fungo ou lodo devido a contato intermitente de água na estrutura. Dois terminais apresentaram ninhos de concretagem e um, eflorescência. 
Tabela 1. Ocorrência das manifestações patológicas por terminal de integração e quantificação absoluta e percentual.

\begin{tabular}{|c|c|c|c|c|c|c|c|}
\hline \multirow{2}{*}{ Manifestação patológica } & \multicolumn{5}{|c|}{ Terminal } & \multicolumn{3}{c|}{ Ocorrência } \\
\cline { 2 - 8 } & T1 & T2 & T3 & T4 & T5 & Absoluta & Percentual \\
\hline Oxidação e corrosão de armadura & $\mathrm{x}$ & & $\mathrm{x}$ & $\mathrm{x}$ & $\mathrm{x}$ & 4 & $80 \%$ \\
\hline Ninhos de concretagem & $\mathrm{x}$ & & $\mathrm{x}$ & & & 2 & $40 \%$ \\
\hline Manchas de fungo/lodo & $\mathrm{x}$ & $\mathrm{x}$ & & & $\mathrm{x}$ & 3 & $60 \%$ \\
\hline Eflorescência & & $\mathrm{x}$ & & & & 1 & $20 \%$ \\
\hline Empoçamento de água em pano de laje & $\mathrm{x}$ & & $\mathrm{x}$ & $\mathrm{x}$ & $\mathrm{x}$ & 4 & $80 \%$ \\
\hline Desplacamento de concreto & $\mathrm{x}$ & & $\mathrm{x}$ & $\mathrm{x}$ & $\mathrm{x}$ & 4 & $80 \%$ \\
\hline Avaria por choque mecânico & $\mathrm{x}$ & & $\mathrm{x}$ & $\mathrm{x}$ & $\mathrm{x}$ & 4 & $80 \%$ \\
\hline Trincas & $\mathrm{x}$ & $\mathrm{x}$ & $\mathrm{x}$ & $\mathrm{x}$ & $\mathrm{x}$ & 5 & $100 \%$ \\
\hline Rachadura & $\mathrm{x}$ & & $\mathrm{x}$ & & $\mathrm{x}$ & 3 & $60 \%$ \\
\hline
\end{tabular}

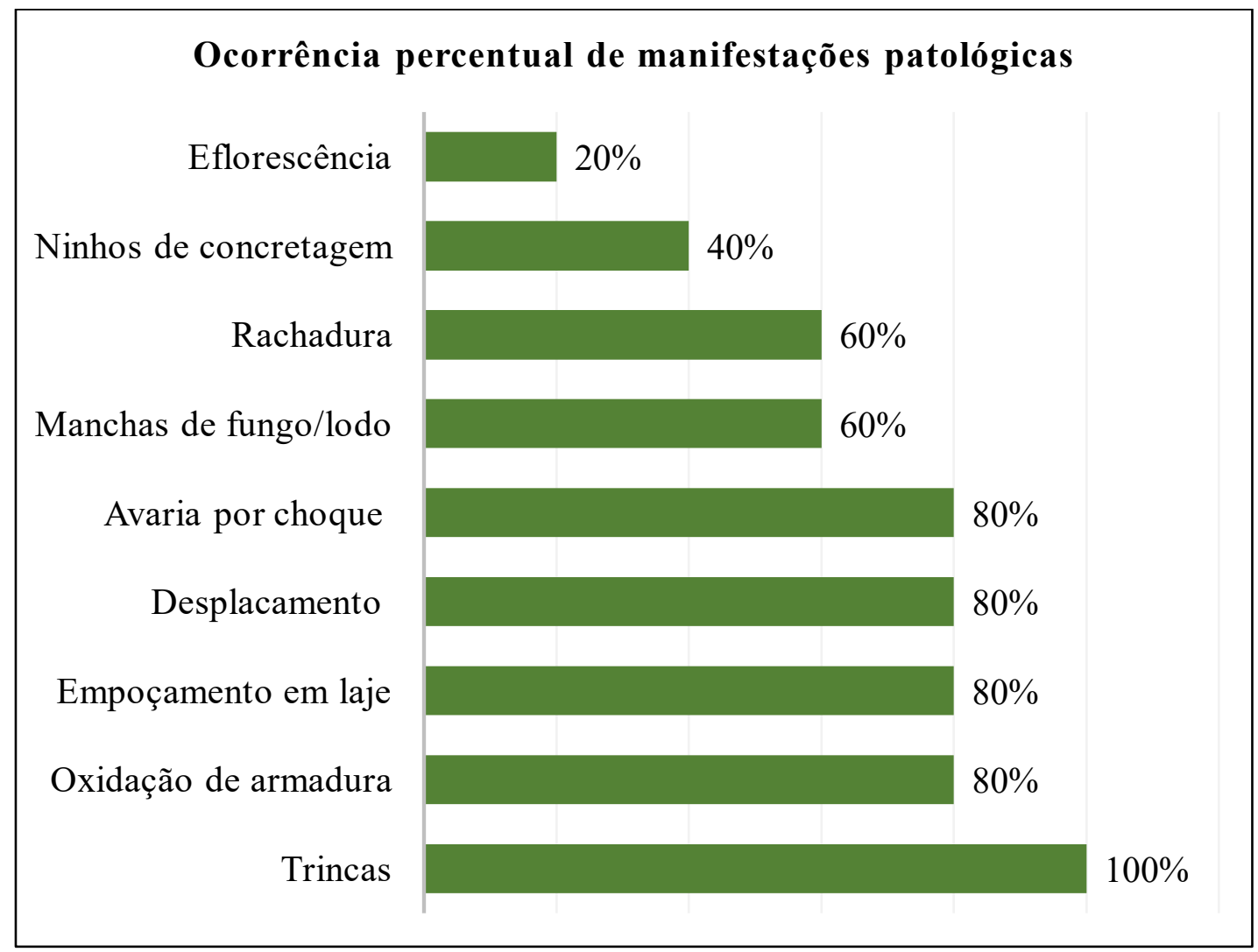

Figura 3. Ocorrência percentual das manifestações patológicas.

\subsection{Oxidação e corrosão de armadura e ninhos de concretagem}

O T2 foi o único terminal onde não se encontrou casos de armadura exposta e, por consequência disso, também foi o único sem casos de oxidação de armadura. Leva-se em conta o fato de este, à época da realização do estudo em campo, ser o terminal de integração com estrutura mais nova de Manaus (reforma inaugurada em 2016). Dos demais terminais, todos apresentaram casos de oxidação de armaduras expostas (Figura 4-A), em maior ou menor grau. Chamou a atenção o fato de que as bases dos pilares são os locais com maior ocorrência de armaduras expostas, principalmente nos Terminais 3, 4 e 5. No T4, em particular, despertou curiosidade um pilar da passarela, que apresentava armadura exposta em sua base com aproximadamente um metro de 
altura (Figura 4-B). Funcionários relataram que aquele local é frequentemente utilizado por motoristas de ônibus como mictório. O contato da urina com o concreto acelera o processo de deterioração, o que explica o agravamento do problema. Pode-se supor também que boa parte dos demais problemas semelhantes estejam relacionados ao mesmo agravante, pois verificou-se a presença de cachorros usando os pilares para o mesmo fim. Além disso, foram encontrados também assentos de concreto com armaduras expostas e concreto desplacado (Figura 4-C).

Os Terminais 1 e 3 apresentaram casos de ninho de concretagem (Figura 4-D), que, apesar de serem falhas de execução comprometedoras da estética estrutural, podem ter seus efeitos contornados pela rápida ação de tratamento, já que existem de forma localizada e em pequenas quantidades em relação ao elemento estrutural e ao tamanho total das edificações.

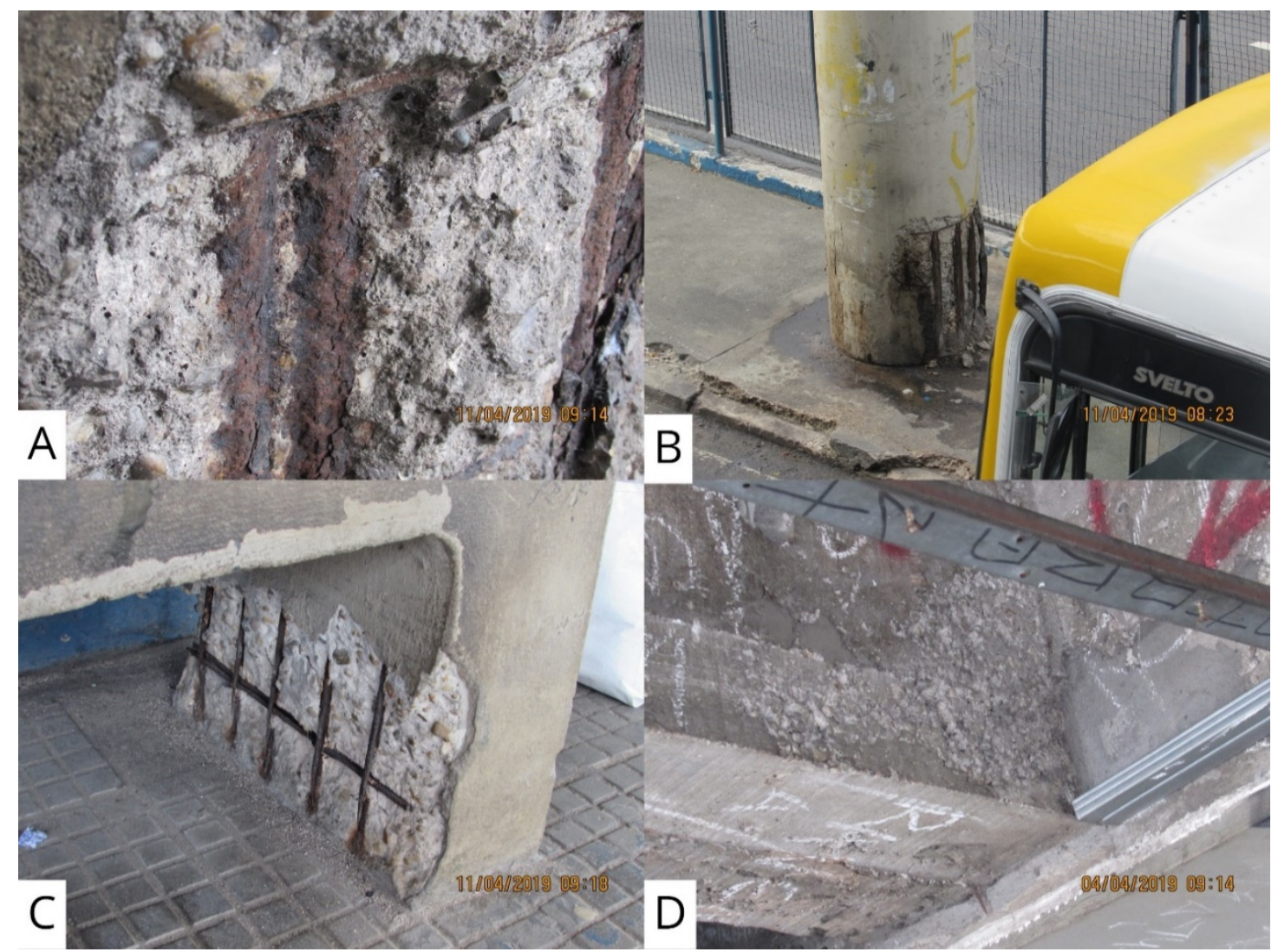

Figura 4. A: No T4, base de pilar com armadura exposta em estágio avançado de oxidação; B: No

T4, base de pilar de passarela com armadura exposta em alto grau de corrosão; C: Base de assento de concreto desplacada e com armadura exposta no T4; D: Viga no T3 apresentando ninhos de concretagem gerados na execução do elemento estrutural.

\subsection{Manifestações patológicas relacionadas à presença de água}

Todos os terminais apresentaram problemas relacionados à presença de água. Diz o dito popular que "água mole em pedra dura, tanto bate até que fura". A frase serve para destacar que o cuidado com as manifestações patológicas geradas pela presença indevida de água deve ser de especial importância, pois é comum que a falta de tratamento leve a problemas mais graves, que se acumulam ao longo do tempo.

Foi constatado empoçamento de laje (Figura 5-A) em quatro dos cinco terminais, ou, observando de outro ângulo, na totalidade das possibilidades, já que o único a não apresentar esse problema, o $\mathrm{T} 2$, tem salas internas com paredes em alvenaria e lajes de cobertura, protegidas de água de chuva pela cobertura metálica. $\mathrm{O}$ empoçamento favorece a infiltração porque a água presente nele entra nos poros do concreto e pode promover o fenômeno de eflorescência. Apesar disso, o T2 foi o 
único a apresentar eflorescência, ainda em estágio inicial (Figura 5-B/C), em parede de alvenaria da plataforma no sentido bairro, cuja face externa não possui acabamento de argamassa. Em três casos foi constatada presença de manchas de fungo e/ou lodo, ocasionados por infiltração e água intermitente combinadas. Há casos também em que isso ocorre em pontos abaixo de onde há falha na cobertura da edificação e abaixo de tubulações avariadas (Figura 5-D).

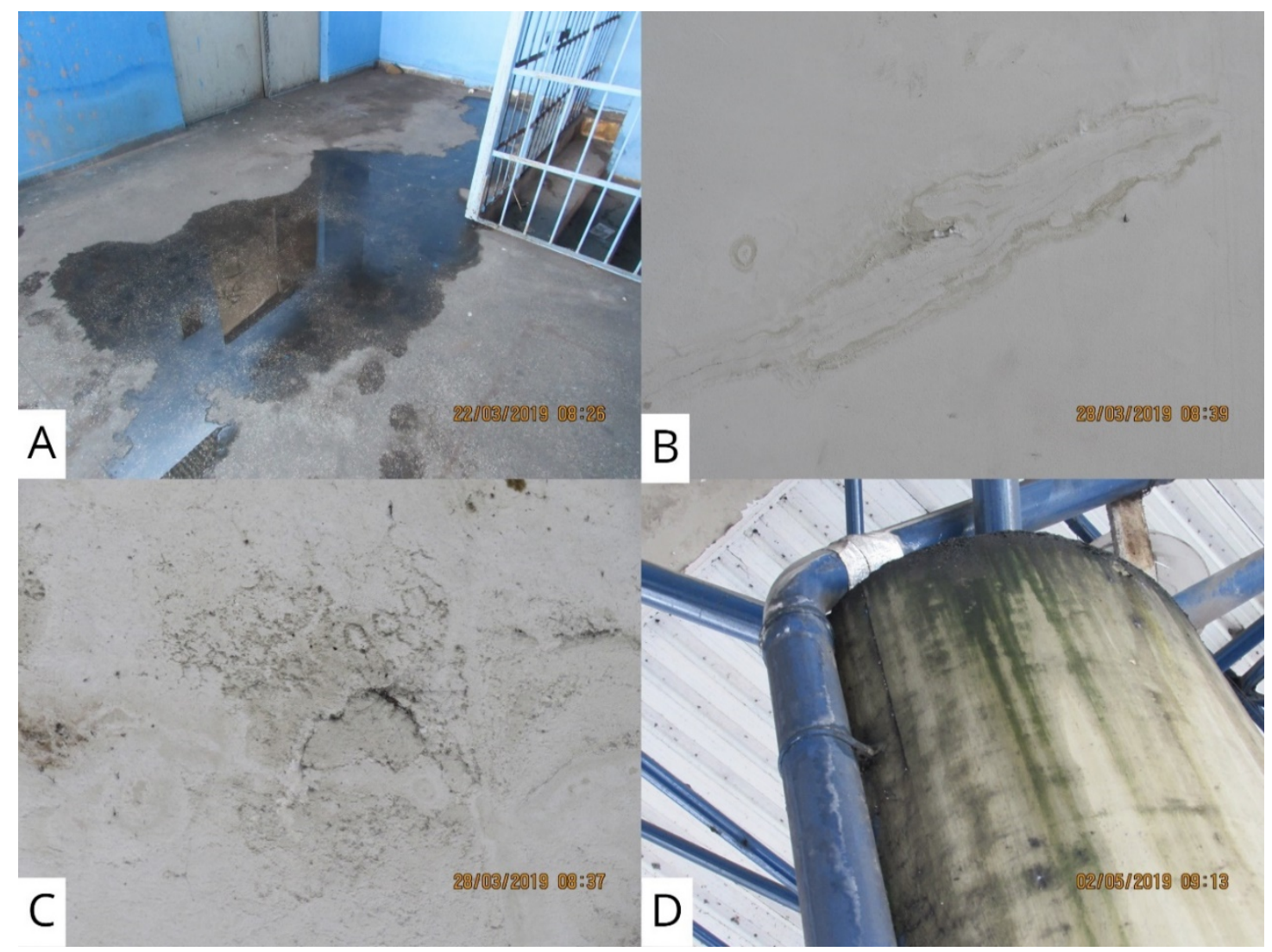

Figura 5. A: Ponto de empoçamento na laje do mezanino do T1; B: Eflorescência na parede do T2 (1/2); C: Eflorescência na parede do T2 (2/2); D: Pilar de concreto com formação de lodo abaixo de tubulação avariada no T5.

\subsection{Desplacamento de concreto, trincas, rachaduras e avarias por choque mecânico}

Há três fenômenos que notadamente ocorrem em todos os terminais e viabilizam problemas no concreto: vibração por conta do fluxo de veículos pesados, carbonatação pela presença massiva de emissores de gás carbônico em um único local e choques mecânicos acidentais ou intencionais por vandalismo. Considerando essas condições a que estão expostas as edificações, as anomalias encontradas condizem com os fenômenos que as precedem. Rachaduras foram vistas em três dos cinco casos, aparentemente causadas por sobrecarga estrutural (Figura 6-A). Quatro terminais apresentaram elementos estruturais com desplacamento de camadas de concreto, sendo que os casos do T3, T4 e T5 isso acontece majoritariamente nas bases de pilares (Figura 6-B/C). Pode-se adicionar aqui também a presença de urina humana e de animais como agravante, segundo o que já foi comentado em 4.1. No T1, esse desplacamento foi verificado na superfície inferior da laje do mezanino. Os mesmos quatro terminais também apresentaram avarias por choque mecânico (Figura 6-D), que podem ocorrer de forma acidental ou intencional por vandalismo. 


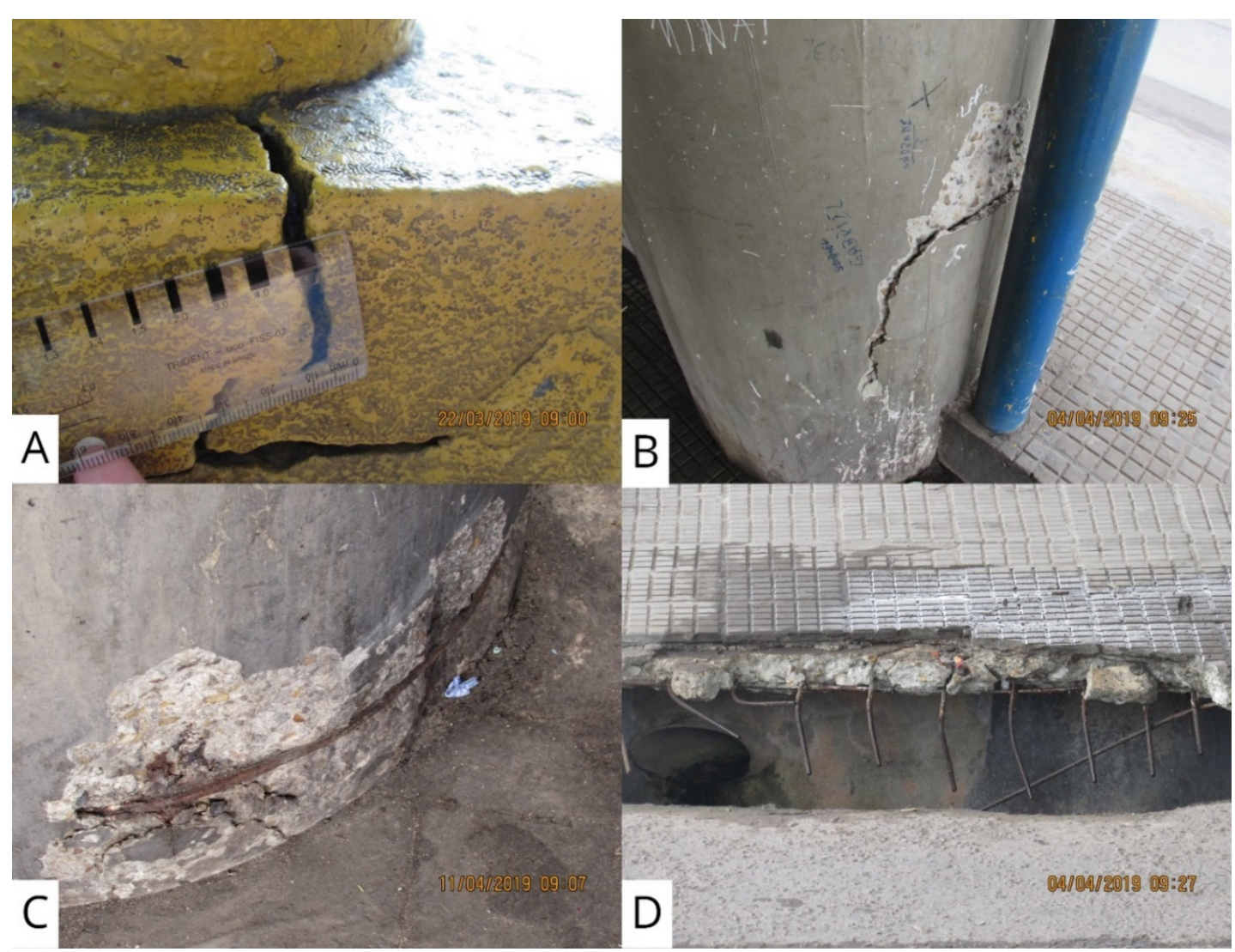

Figura 6. A: Rachadura em base de pilar do T1; B: Desplacamento de concreto em base de pilar no T3; C: Desplacamento de concreto em base de pilar no T4; D: Estrutura do sistema de drenagem pluvial avariada por choque mecânico no T3.

\subsection{Classificação das anomalias quanto ao grau de risco e tratamento}

As manifestações patológicas tiveram seu risco avaliado e classificado (Tabela 2) conforme a Norma de Inspeção Predial Nacional (IBAPE, 2012), em Crítico (1), com recomendação de intervenção e tratamento imediato por comprometer a segurança e a saúde das pessoas e do meio ambiente; Médio (2), podendo a intervenção ser programada a curto prazo pelo fato de o dano comprometer o a funcionalidade e desempenho da edificação, mas sem prejudicar a operação de sistemas; Mínimo (3), podendo a intervenção ser feita a médio prazo pelo fato de os danos estarem mais relacionados à estética que à funcionalidade da edificação.

Tabela 2. Classificação das manifestações patológicas encontradas quanto ao grau de risco.

\begin{tabular}{|c|c|c|c|c|c|}
\hline \multirow{2}{*}{ Manifestação patológica } & \multicolumn{5}{|c|}{ Terminal } \\
\cline { 2 - 6 } & T1 & T2 & T3 & T4 & T5 \\
\hline Oxidação e corrosão de armadura & 2 & 0 & 2 & 1 & 2 \\
\hline Ninhos de concretagem & 2 & 0 & 2 & 0 & 0 \\
\hline Manchas de fungo/lodo & 3 & 2 & 0 & 0 & 2 \\
\hline Eflorescência & 0 & 2 & 0 & 0 & 0 \\
\hline Empoçamento de água em pano de laje & 1 & 0 & 2 & 2 & 2 \\
\hline Desplacamento de concreto & 3 & 0 & 2 & 1 & 2 \\
\hline Avaria por choque mecânico & 3 & 0 & 3 & 3 & 3 \\
\hline Trincas & 3 & 3 & 3 & 3 & 3 \\
\hline Rachadura & 2 & 0 & 2 & 0 & 2 \\
\hline
\end{tabular}


$\mathrm{Na}$ análise do estado geral de conservação, pode-se dizer que os terminais de integração apresentam risco médio, porque as anomalias predominantemente encontradas não comprometem a operação dos sistemas, mas o fazem com a funcionalidade e desempenho. Os terminais 2,3 e 5 são os que melhor se enquadram nessa classificação, já que os problemas encontrados variam de grau médio a mínimo, observando-se o T2 como o que apresentou menor variedade de manifestações patológicas. O T1 e o T4 apresentaram situações isoladas de risco crítico, com possibilidade danos à operação dos sistemas e à segurança e à saúde dos usuários, especialmente em se falando de desplacamento de camadas de concreto associada a oxidação e corrosão de armadura. Logo, sugere-se a seguinte ordem de intervenção: T4, T1, T3, T5, T2.

Para oxidação e corrosão de armadura, recomenda-se a recuperação utilizando a metodologia proposta por Helene (1986), com aplicação de anticorrosivo para prevenir novas ocorrências. Para os ninhos de concretagem decorrentes de falhas executivas e desplacamento de concreto devido à carbonatação, o preenchimento com graute é uma boa alternativa para manter uniformidade em relação à estrutura e recuperar a camada passivadora das armaduras expostas. Para os casos de manchas de fungo, lodo e eflorescência decorrentes de infiltrações, além da limpeza local com hipoclorito, impermeabilização e aplicação de argamassa nas paredes externas, uma solução interessante é a correção das infiltrações por meio da injeção de líquido elástico polivinílico. Nas regiões de empoçamento sobre pano de laje, é necessário fazer o nivelamento do piso, mantendo inclinação razoável, de modo a garantir escoamento da água. No caso de trincas e fissuras passivas decorrentes de vibrações, a aplicação de selante devolve a harmonia visual. As rachaduras, no entanto, devem continuar a ser monitoradas, a fim de avaliar seu desenvolvimento ao longo do tempo e impacto na segurança estrutural.

\section{CONCLUSÕES}

Verificou-se que as manifestações patológicas em estruturas de concreto encontradas têm efeito negativo sobre a ergonomia ambiental dos terminais de integração de Manaus, impactando a experiência do usuário de transporte coletivo.

Dentre as manifestações patológicas encontradas, destacam-se as trincas, desplacamento de concreto e corrosão de armaduras em vigas e pilares. Estes problemas são causados pela qualidade dos materiais utilizados na execução das obras e agravados pelas condições a que são expostos durante sua utilização, o que significa, nos casos verificados, presença eventual de urina humana e animal nos locais, alta concentração de gás carbônico $\left(\mathrm{CO}_{2}\right)$ emitido pelos motores dos ônibus, que favorece a carbonatação do concreto, vibração por longos períodos de tempo, devido à massiva circulação de veículos pesados. Há também de se destacar a presença de empoçamento de lajes em quase todos os casos, causados por drenagem inadequada ou ausente, que pode gerar infiltrações; e avarias por choque mecânico, especialmente causadas por atos de vandalismo.

Em mais de uma ocasião, permissionários reclamaram sobre anomalias estruturais visíveis em alguns elementos e como isso afeta sua rotina de trabalho, especialmente quando em ocasiões de chuva produtos são molhados e o espaço de circulação é limitado por conta de alguma falha de projeto ou executiva que favorece a entrada de água na parte interna da edificação. Além disso, usuários também comentaram o fato de alguns assentos de concreto estarem danificados e com armaduras expostas, diminuindo o conforto no espaço de espera pelo ônibus. Outro ponto negativo comum a todos os terminais de ônibus é o estado de conservação dos banheiros, que apresentam significativos problemas causados pela depredação de tetos, vasos sanitários e divisórias, agravados por empoçamento do piso da laje. Desta forma, recomendou-se que fosse programada manutenção, baseando-se no grau de risco das manifestações patológicas apresentados na Tabela 2, seguindo o proposto no subitem 4.4 deste trabalho. 
Os resultados deste estudo foram entregues à Secretaria Municipal de Infraestrutura em junho de 2019. Em outubro de 2019, o relatório final da pesquisa foi apresentado, como atividade obrigatória do Programa Institucional de Bolsas de Iniciação Científica e sem gerar publicação de resumo ou artigo em anais, no Congresso de Iniciação Científica (XXVIII CONIC-UFAM), evento interno da Universidade Federal do Amazonas. Em maio de 2020 foram anunciadas obras para a estrutura viária da cidade de Manaus. Entre elas, destaca-se a demolição do Terminal 1 para construção de um novo, com arquitetura modificada e adequações ergonômicas. O novo T1 foi entregue aos cidadãos manauaras em 17 de maio de 2021. Nesse meio tempo, os demais terminais de ônibus também receberam obras de reparo em alguns dos locais de atenção apontados neste trabalho.

\section{AGRADECIMENTOS}

Os autores agradecem à Secretaria Municipal de Infraestrutura de Manaus pelo apoio prestado durante as visitas técnicas e consulta aos projetos, também à Fundação de Amparo à Pesquisa do Estado do Amazonas e ao Conselho Nacional de Desenvolvimento Científico e Tecnológico pela concessão de bolsas, e à Universidade Federal do Amazonas pelo incentivo às atividades de pesquisa por meio do Programa Institucional de Bolsas de Iniciação Científica.

\section{REFERÊNCIAS}

Associação Brasileira de Normas Técnicas. (2014). NBR 6118: Projeto de estruturas de concreto - Procedimento. Rio de Janeiro.

BARBOSA FILHA, L. D. et al. (2016). "Metodologia para a recuperação de pilares submetidos à carbonatação: apresentação de caso de um prédio residencial multifamiliar de térreo em pilotis de Manaus/AM" in: B. Tutikian et. al. (org.), Anais do Congresso Brasileiro de Patologia das Construções CBPAT 2016. $6^{\mathrm{a}}$ conferência sobre patologia e reabilitação de edifícios, Belém: PA.

BOLINA, F. L. et. al. (2019), “Patologia de estruturas”. Oficina de Textos, São Paulo: SP.

BRASIL. Constituição (1988), "Constituição da República Federativa do Brasil de 1988”. Disponível em: <http://www.planalto.gov.br/ccivil_03/Constituicao/Constituicao.htm>. Acesso em: 10 ago. 2021.

Empresa Municipal de Transportes Urbanos (2012), “Planta Baixa - Terminal 1”. Prefeitura de Manaus, Manaus: AM.

Google Maps (2021), “Mapa da cidade de Manaus”. Disponível em: <maps.google.com>. Acesso em 31 de maio de 2021.

HELENE, P. R. L. (1986), “Corrosão em armaduras para concreto armado”. Pini, São Paulo:SP.

Instituto Brasileiro de Avaliações e Perícias de Engenharia, (2012), "Norma De Inspeção Predial Nacional”. Ibape, São Paulo: SP. Disponível em: <http://ibape-nacional.com.br/biblioteca/wpcontent/uploads/2012/12/Norma-de-Inspe\%C3\%A7\%C3\%A3o-Predial-IBAPE-Nacional.pdf $>$.

Acesso em: 11 ago. 2021.

Instituto Nacional de Meteorologia, "Gráficos climatológicos". Disponível em: $<$ https://tempo.inmet.gov.br/>. Acesso em: 11 ago. 2021. 
JUNIOR, I. G. S.; RANGEL, T. L. V. (2017), “O direito social ao transporte: mobilidade urbana e meio de promoção de direitos fundamentais". Âmbito Jurídico. Rio Grande, Ano 20, n. 163. Disponível em: <https://ambitojuridico.com.br/cadernos/direito-constitucional/o-direito-socialao-transporte-mobilidade-urbana-e-meio-de-promocao-de-direitos-fundamentais/>. Acesso em: 11 ago. 2021.

LEITE, C. E.; LOPES, G. S.; BARREIRO, J. H. L. C. D. (2015), “A influência do transporte na qualidade de vida e motivação no trabalho". In: CONGRESSO NACIONAL DE EXCELÊNCIA EM GESTÃO, 11., 2015, Rio de Janeiro. Anais. Universidade Federal Fluminense, Rio de Janeiro: RJ. Disponível em: <http://www.inovarse.org/node/4089>. Acesso em: 11 ago. 2021.

MANAUS. Superintendência Municipal de Transportes Urbanos (2018), "O que é Integração Temporal”. Disponível em: <https://immutransporte.manaus.am.gov.br/o-que-e-integracaotemporal/>. Acesso em: 10 ago. 2021.

NASTA, A. P. S. (2014), “Design, ergonomia e sustentabilidade ambiental em sistemas de abrigos de onibus em Belo Horizonte”. 185 f. Tese (Mestrado) - Curso de Mestrado em Design, Universidade do Estado de Minas Gerais, Belo Horizonte:MG. Disponível em: $<$ http://anapaulanasta.com/wpcontent/uploads/2014/12/Disserta\%C3\%A7\%C3\%A3o_AnaPaulaNasta.pdf $>$. Acesso em: 10 ago. 2021.

“Passageiros criticam situação de banheiros em terminais de ônibus em Manaus”. Produção de Samira Benoliel (2018). Manaus: Rede Amazônica. Disponível em: $<$ https://globoplay.globo.com/v/6594845/ >. Acesso em: 10 ago. 2021.

PAULETTI, C. (2009), "Estimativa da carbonatação natural de materiais cimentícios a partir de ensaios acelerados e de modelos de predição". $285 \mathrm{f}$. Tese (Doutorado) - Programa de PósGraduação em Engenharia Civil, Universidade Federal do Rio Grande do Sul, Porto Alegre: RS. Disponível em: $<$ https://www.lume.ufrgs.br/bitstream/handle/10183/30120/000778056.pdf?sequence=1\&isAllow ed=y>. Acesso em: 10 ago. 2021.

POGGIALI, F. S. J. (2009), “Durabilidade de estruturas de concreto em usinas siderúrgicas”. 81 f. Monografia (Especialização) - Curso de Especialização em Construção Civil, Universidade Federal de Minas Gerais, Belo Horizonte: MG.

SOUZA, V. C. M.; RIPPER, V. (1998), "Patologia, recuperação e reforço de estruturas de concreto armado”. Pini, São Paulo:SP.

UEMOTO, K. L. (1988), “Patologia: danos causados por eflorescência”. In: Instituto de Pesquisas Tecnológicas (Org.). Tecnologia de Edificações. Pini, São Paulo: SP.

VIEIRA, M. A. (2016), “Patologias Construtivas: Conceito, Origens e Método de Tratamento”. Especialize, v. 01/2016, n. 12, p. 1-15, Goiânia: GO. Mensal. ISSN 2179-5568. 